CLOSED REDUCTION OF PRIMARY ANTERIOR SHOULDER DISLOCATIONS - AN APPROACH WITHOUT ANAESTHESIA AND ANALGESIA.
KEY WORDS: Anterior dislocation, Glenohumeral, Reduction, Shoulder dislocation

\section{Dr. Gaurav}

Bhutada

Dr. Mohammed

Faizan*

Dr. Karan Mane
Orthopaedic Trauma and Spine Surgeon, Nagpur, India.

Consultant Orthopaedic and Spine Surgeon, West Avenue Medical Center, Nagpur, India. *Corresponding Author

Consultant Orthopaedic Surgeon, Ikon Hospital, Nagpur, India.

A new maneuver for anterior shoulder dislocation has been advocated in this case series of 40 patients, which did not require anesthesia, analgesia, pre-medications, assistance, traction. It is an effective and easy to do maneuver and has been successful in $95 \%$ of patients. Literature has described many methods for anterior shoulder dislocation, but this stands unique also in view that it is painless for the patient.

\section{INTRODUCTION-}

Glenohumeral joint of the shoulder is the most commonly dislocated joint in the human body and accounts for $45 \%$ of all dislocations. ${ }^{1,2}$ Acute dislocation is a surgical emergency and demands urgent relocation. Anterior dislocation of the shoulder is commonly seen in accident and emergency and trauma clinics and account to about $95 \%$ of all the shoulder dislocations.

These patients often present in a manner that a trained trauma physician can recognize at presentation itself. The arm is usually held in abduction and internal rotation. Physical examination reveals loss of normal contour of the deltoid and the acromion is prominent posteriorly and laterally. ${ }^{1}$

Occasionally such cases are missed or present with fracture of proximal humerus especially when they receive treatment from unqualified practitioners who commonly practise in rural areas. Owing to paucity of the literature, no standard treatment protocol exists for neglected anterior dislocation of the shoulder, though most such chronic cases are managed by open reduction. ${ }^{3}$

Acute treatment of a dislocated shoulder is closed reduction, which should be performed as soon as possible, either on the field or in an emergency department. ${ }^{4}$

\section{METHOD -}

This study was conducted in 40 patients presenting in the emergency department at a tertiary care hospital over a period of 6 months. The diagnosis was confirmed by clinical examination and X-ray after obtaining a brief history. A thorough neurovascular examination of the involved extremity was carried out. A written informed consent was taken from the patient before attempting the reduction. In this manoeuvre, the surgeon either stands by the side of the patient of at his back, while the patient is made to sit on a chair with back rest and pushes his back against the chair so as to fix the scapula. Traction has no role in this method. The forearm is held by the elbow and wrist.

Gentle adduction to the arm is given by drawing the elbow towards the flank (midline). With forearm in supination, the arm is subjected to gentle external rotation very slowly over a 2-3 minute. The most important step to remember is to keeping the patient engaged in conversation so as to relax the patient and divert the attention to avoid any undue or voluntary muscular spasms. Automatic reduction has been observed in almost all cases without any additional manoeuvre, which is felt as a clunk and patient tells of sudden relief. The limb is then internally rotated so that the fingers touch the opposite shoulder and a sling is given to the patient in that position.

Radiographs confirm successful reduction.

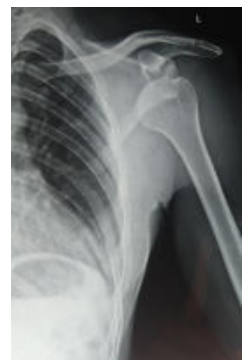

Figure 1-Showing dislocation of left shoulder

\section{Observation and results -}

It was noted that all the patients were males and mostly the dislocation resulted due to sustaining a fall, industrial injury, and less likely by a vehicular accident. 95\% patients were successfully treated with this method which presented with acute dislocation of shoulder.

These patients were aged between 22 and 65 years with male preponderance.

Most of the patients had presented to the clinics within 2 hours of the primary dislocation and the average time taken for the reduction after explaining the procedure and obtaining the consent was 3 to 5 minutes. All the successful reductions were done in a single attempt with non-reduction in 2 cases who had presented later than 1 week after primary reduction.

One of these patients had already undergone multiple attempts by traction-counter-traction method but the reduction was not achieved and had to undergo closed reduction under general anesthesia.

No other complications were noted in any of the cases.

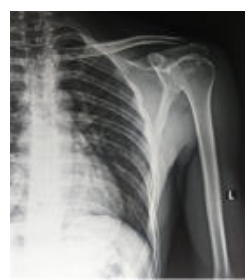

Figure 2 - Post-reduction X-ray 


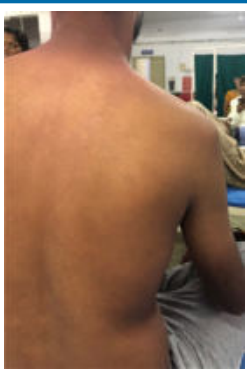

Figure 3 - Another patient with right shoulder dislocation. The surgeon stands behind the patient while performing the reduction maneuver.

\section{DISCUSSION-}

More than $50-60 \%$ of dislocations of large joints involve the shoulder (glenohumeral). ${ }^{5,}{ }^{6} \mathrm{Up}$ to $90-96 \%$ of shoulder dislocations are antero-inferior. ${ }^{7,8}$ Most dislocations can be reduced in the emergency department using simple methods. The ideal method should be simple, easy, quick, effective, atraumatic, pain-free, require little assistance or medication, and cause no additional injury to the shoulder joint, musculoskeletal or neurovascular structures. ${ }^{9,10}$ All methods deploy traction in some form or the other, and this is combined with rotations, translations, scapular movements, counter tractions, direct pushing in of the head, etc. ${ }^{11,12}$ The methods described include traction-counter-traction in adduction (Hippocrates) ${ }^{13}$, in forward flexion (Stimson and Spaso), in lateral elevation (Eskimos), with leverage (Kocher and Milch), scapular manipulation, and other methods using direct pressure or pushes. The existence of plethora of methods spells the fact that not one method is fool proof or guaranteed to work all the time. Other methods are fist in axilla $^{12}$, direct knee pressure ${ }^{14,15}$ sheets or straps to pull out the axilla ${ }^{15}$ pulling the arm over the back of a chair ${ }^{16,17}$ Simpson's hanging arm method ${ }^{18,19}$ reverse Spaso ${ }^{20,21}$ painful selfreduction method of Boss-Holzach ${ }^{22}$ Milch and its variants, Leidelmeyer's external rotation method, Scapular manipulations and other miscellaneous methods ${ }^{23}$. Many of these methods have been called easy, revolutionary, new or simple by their inventors and proponents. However, the success with all these procedures and methods varies tremendously and the success rate has been variously reported.

This method is one of the most effective and efficient for treating acute shoulder dislocation. In this study, we determined that the average time required for successful reduction was about 3-5 minutes. Almost all patients had a significant VAS score improvement immediately after the reduction was achieved. None of these patients who were successfully treated required any analgesia or anesthesia.

By this method, it was not possible to reduce a neglected chronic dislocation in a 50-year-old male, who presented after almost 1 month of dislocation.

This method is different from the others hitherto published, because the exact combination of movements to be performed in an erect position, without any traction, anaesthesia or analgesia, leading to a hundred percent successful reduction, has not been previously described. ${ }^{2}$

\section{REFERENCES -}

1. Cutts S, Prempeh M, Drew S. Anterior shoulder dislocation. Ann R Coll Surg Engl. 2009;91(1):2-7.

2. L Prakash. A New Method for Reduction of Shoulder Dislocations. Ortho Surg Ortho Care Int J . 1(3).OOIJ.000511.2018.

3. Chaudhary D, Joshi D, Jain V, Mohindra M, Mehta N. A six months old neglected anterior shoulder dislocation managed by closed reduction and Latarjet procedure. Chin JTraumatol.2016;19(5):295-297.

4. Youm T, Takemoto R, Park BK. Acute management of shoulder dislocations. J Am Acad Orthop Surg 2014;22:761-71.

5. Kocher $\mathrm{T}(1870)$ Eine neue Reductionsmethode fur Schutiterverrenkung. Berlin KlinWehnschr 7:101-105.

6. Plummer D, Clinton J (1989) The external rotation method for reduction of acute anterior shoulder dislocation. Emergency Medicine Clinics of North America 7(1): 165-175.

7. McNamara RM (1993) Reduction of anterior shoulder dislocations by scapular manipulation. Ann Emerg Med 22 (7): 1140-1144.

8. Daya M (1998) Shoulder. In: Rosen P, Barkin (Eds.), Emergency medicine: concepts and clinical practice, (4th edn), St.Louis:Mosby, USA, pp. 728- 729.

9. leeson AP (1998) Anterior glenohumeral dislocations: what to do and how to do it.J Accid Emerg Med 15(1): 7-12.

10. Uehara DT, Rudzinski JP (2000) Injuries to the shoulder complex and humerus. In: Tintinalli JE, Kelen DG, Stapczynski JS, (Eds.), Emergency Medicine: a comprehensive study guide, (5th edn), Mcgraw- Hill, USA, pp. 1783-1791.

11. Nicola T (1949) Acute anterior dislocation of the shoulder. J Bone Jt Surg Am 31:351.

12. Mattick A, Wyatt JP (2000) From Hippocrates to the Eskimo- -a history of techniques used to reduce anterior dislocation of the shoulder. J R Coll Surg Edinb 45(5):312-316

13. Adams F (2003) The internet classics archive: Instruments of reduction by Hippocrates.

14. Boger D, Sipsey J, Anderson G (1984) New traction devices to aid reduction of shoulder dislocations. Ann Emerg Med 13(6):423-425.

15. Westin CD, Gill EA, Noyes ME, Hubbard M (1995) Anterior shoulder dislocation. A simple and rapid method for reduction. Am J Sports Med 23(3): 369-371.

16. Noordeen MH, Bacarese Hamilton IH, Belham GJ, Kirwan EO (1992) Anterior dislocation of the shoulder: a simple method of reduction. Injury 23(7): 479480.

17. Lippert FG (1982) A modification of the gravity method of reducing anterior shoulder dislocations. Clin Orthop Relat Res 165:259-260.

18. Yuen MC, Yap PG, Chan YT, Tung WK (2001) An easy method to reduce anterior shoulder dislocation: The Spaso technique. Emergency Medicine Journal 18(5):370-372.

19. Yuen MC,Yap PG, Chan YT, Tung WK (1999) The Spaso technique in reduction of anterior shoulder dislocation in the Accident and Emergency Department of Kwong Wah Hospital (Hong Kong). Prehospital and Disaster Medicine 14(supplement 1):S78.

20. Yuen MC, Tung WK (2001) Reducing anterior shoulder dislocation by the Spaso technique. Hong Kong Journal of Emergency Medicine 8: 96- 100.

21. Yuen MC, Tung WK (2001) The use of the Spaso technique in a patient with bilateral dislocations of shoulder. Am J Emerg Med 19(1):64-66.

22. Janecki CJ, Shahcheragh GH (1982) The forward elevation maneuver for reduction of anterior dislocations of the shoulder. Clin Orthop Relat Res 164: 177-180.

23. McNair TJ (1957) A clinical trial of the hanging arm reduction of dislocation of the shoulder.J R Coll Surg Edinb 3(1):47-53. 